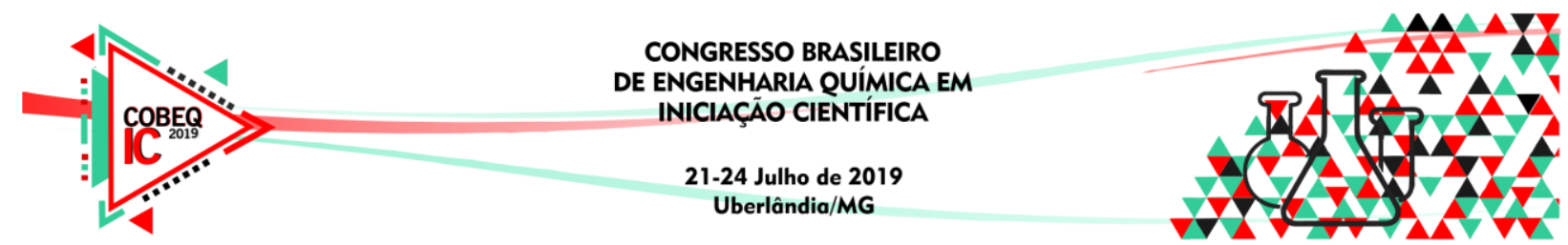

\title{
PRODUÇÃO DE MEMBRANA ANIÔNICA PARA APLICAÇÃO EM CÉLULA DE DIÁLISE
}

\author{
L. L. FERNANDES ${ }^{1}$, M. S. RODRIGUES ${ }^{1}$, V. L. CARDOSO ${ }^{1}$, M. M. RESENDE ${ }^{1}$ \\ ${ }^{1}$ Universidade Federal de Uberlândia, Faculdade de Engenharia Química \\ E-mail para contato: lfernandes.lorena@gmail.com
}

\begin{abstract}
RESUMO - A preocupação ambiental tem se tornado cada vez maior, fazendo com que o uso de tecnologias limpas sejam utilizadas com maior frequência no intuito de reduzir o impacto ambiental. Dessa forma, o uso de membranas poliméricas de troca iônica aparece como uma boa alternativa para os tratamentos de efluentes devido à alta taxa de permeabilidade graças à sua capacidade de formar um fino filme de baixo custo se comparado às membranas inorgânicas. Umas das técnicas de separação por membranas utilizadas é a diálise que utiliza o potencial químico como força motriz para promover um fluxo de contra íons do receptor para a alimentação. Por se tratar de uma tecnologia nova no Brasil, as membranas possuem custo elevado para as indústrias nacionais por ser um produto importado. Sob esta perspectiva, o principal objetivo deste trabalho é produzir membranas poliméricas aniônicas e estimar a eficiência do transporte iônico por meio das membranas utilizando a técnica da diálise, no intuito de diminuir os gastos de produção e, assim, propor como uma alternativa às membranas importadas. As membranas avaliadas apresentaram permeabilidade de $34,48 \mathrm{~L} / \mathrm{m}^{2} \mathrm{~h}$ e IEC de 0,19 prótons de $\mathrm{H}^{+} / \mathrm{gM}_{\text {seca }}$ com a resina DUOLITE AP143/1083, que mostraram boa troca iônica avaliada pela condutividade vs tempo e $\mathrm{pH}$ vs tempo, mostrando-se como uma boa opção para o estudo de membranas de troca iônica.
\end{abstract}

\section{INTRODUÇÃO}

A preservação do meio ambiente vendo sendo um aspecto essencial para as diversas atividades industriais. Cada vez mais se torna necessário a busca por novas soluções e reduções nos impactos ambientais, contribuindo, assim, para estudos visando à recuperação e reaproveitamento de resíduos e produtos secundários indesejáveis gerados nas indústrias. $\mathrm{O}$ uso de tecnologias limpas, como os procedimentos que utilizam membranas para separação de espécies químicas iônicas e não iônicas, tem sido adotadas no tratamento de vários efluentes. Membranas podem ser definidas como filtros ou barreiras seletivas que tem por objetivo separar duas fases, por meio de uma força motriz, impedindo parcial ou totalmente a passagem de uma ou mais espécies químicas que constituem as fases, podendo ser líquida, gasosa ou solução (Anadão, 2010; Meireles et al., 2015; Warsinger et al., 2018).

A classificação das membranas pode ser feita quanto: à origem do material usado em sua fabricação (inorgânico ou orgânico); à estrutura (assimétrica ou simétrica); à configuração (formato cilíndrico ou de folhas planas); à técnica de produção (extrusão a quente, inversão de 


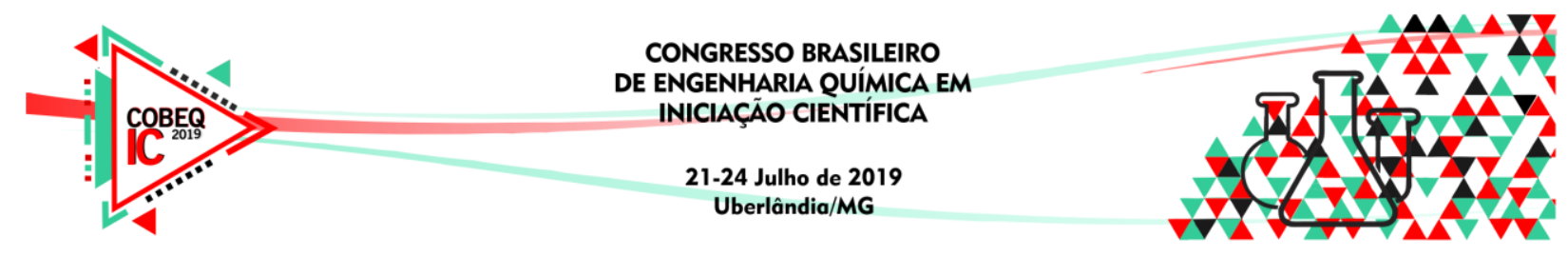

fase, dentre outros); ao método de separação (gradiente de concentração transmembrana de espécies permeáveis à membrana, gradiente de potencial elétrico e gradiente de pressão transmembrana); às aplicações (osmose reversa, diálise, eletrodiálise, ultrafiltração, microfiltração, nanofiltração, separação de gases, pervaporação) (Jeong et al., 2018; Park et al., 2018; Vincent \& Bessarabov, 2017). Dentre técnicas de separação por membranas, a diálise apresenta-se como boa poção por se tratar de um processo econômico, simples e que necessita de baixo gasto de energia (Anadão, 2010).

Entende-se por diálise o processo cuja separação baseia-se na difusão de espécies com mobilidades distintas, por meio de uma membrana semipermeável que usa como força motriz a diferença de potencial químico provocando um fluxo de contra íons do receptor para a alimentação. Esta técnica tem como objetivo realizar a troca de íons até obter o equilíbrio entre as etapas da alimentação e o dialisado. Uma das principais vantagens da diálise, comparada às outras técnicas, é a baixa taxa de fluxo quando a espécie a ser separada é sensível à deterioração mecânica causada por pressões elevadas ou taxas de cisalhamento (Anadão, 2010).

Desta forma, este trabalho tem como objetivo desenvolver membranas de troca iônica para uso em células de diálise com o intuito de diminuir o alto custo das membranas importadas e assim incentivar seu uso em diversos tratamentos de efluentes que necessitem do sistema de troca de íons.

\section{MATERIAL E MÉTODOS}

A membrana polimérica de polissulfona foi preparada com $5 \%$ de incorporação de resina de troca iônica aniônica (DUOLITE AP143/1083). A solução contendo 20\% do polímero e $80 \%$ do solvente N,N-dimetilacetamida foi espalhada sobre um vidro plano e imersa em água para reversão de fase.

A membrana produzida foi testada quanto à permeabilidade com área total de 0,01130 $\mathrm{m}^{2}$ e de acordo com o método apresentado por Engel (2011) e a capacidade de troca iônica em que a membrana foi imersa em solução de $\mathrm{H}_{2} \mathrm{SO}_{4} 0,5 \mathrm{M}$ a $80{ }^{\circ} \mathrm{C}$ por 2 horas e desidratada até massa constante. A amostra de $0,06 \mathrm{~g}$ da membrana protonada foi imersa em solução de $\mathrm{NaCl}$ $2 \mathrm{M}$ por 24 horas para liberação de íons $\mathrm{H}^{+}$. Uma titulação com solução de $\mathrm{NaOH} 4 \mathrm{mM}$ e fenolftaleína como indicador foi realizada para quantificar os prótons liberados na troca iônica. O cálculo da capacidade de troca iônica até a titulação atingir um valor constante é dado pela Equação 1:

$$
I E C=\frac{V_{\mathrm{NaOH}} \times C_{\mathrm{NaOH}}}{M_{\text {seca }}}
$$

onde: $\mathrm{V}_{\mathrm{NaOH}}$ é o volume de $\mathrm{NaOH}$ usado na titulação, $\mathrm{C}_{\mathrm{NaOH}}$ é a concentração de $\mathrm{NaOH}$ usada na titulação e $\mathrm{M}_{\text {seca }}$ é a massa seca da membrana (Jiang, et al., 2010 e Silva, 2011).

Uma célula de diálise foi construída com dois compartimentos e um agitador mecânico em cada compartimento. Uma solução de $\mathrm{NaCl} 0,1 \mathrm{M}$ foi colocada em um compartimento e uma solução de $\mathrm{HCl}$ 0,1 M foi colocada no outro compartimento, separados pela membrana 


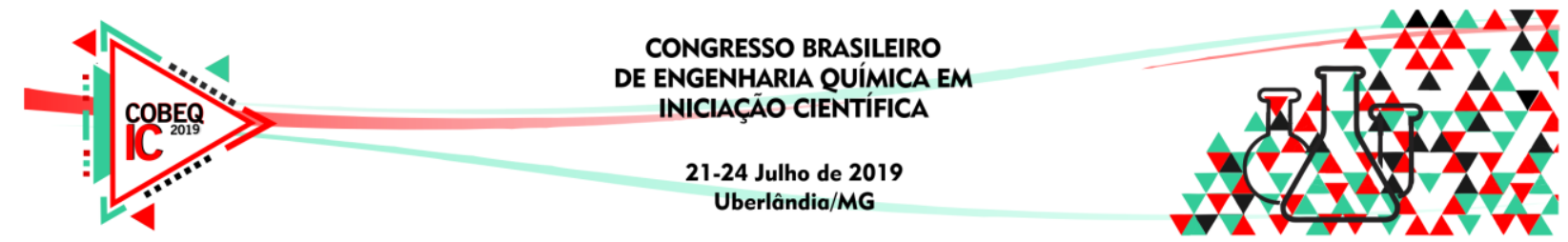

polimérica de polissulfona incorporando 5\% de massa de resina de troca iônica. Leituras de pH foram realizadas ao longo do tempo para monitorar a troca iônica da solução.

\section{RESULTADOS E DISCUSSÕES}

A membrana em estudo apresentou um fluxo de permeabilidade de $34,48 \mathrm{~L} / \mathrm{m}^{2} \mathrm{~h}$. Os valores obtidos de IEC foram realizados em triplicata e apresentaram um valor médio de 0,19 prótons de $\mathrm{H}^{+} / \mathrm{gM}_{\text {seca }}$. A Figura 1-(A) mostra a condutividade em 48 horas e a Figura 1-(B) mostra o gráfico da leitura do $\mathrm{pH}$ no mesmo período.

Através da Figura 1-(B), é possível notar que a solução de $\mathrm{NaCl}$ reduz rapidamente o $\mathrm{pH}$ nas primeiras horas. $\mathrm{O}$ mesmo acontece com a condutividade, onde as análises de ambas as soluções têm comportamentos semelhantes. Após as 7 horas iniciais do experimento é possível observar que o $\mathrm{pH}$ do $\mathrm{HCl}$ aumenta ligeiramente de forma linear, nota-se também que nesse mesmo período a condutividade do $\mathrm{NaCl}$ tende a manter-se constante até entrar em equilíbrio com o $\mathrm{HCl}$ próximo às 48 horas de análise do experimento. Tal comportamento é devido à baixa permeabilidade da membrana e a taxa de íons suficientes presentes na Resina DUOLITE AP143/1083.

Figura 1 - A) Variação da condutividade ao longo do tempo; B) Variação do pH ao longo do tempo.

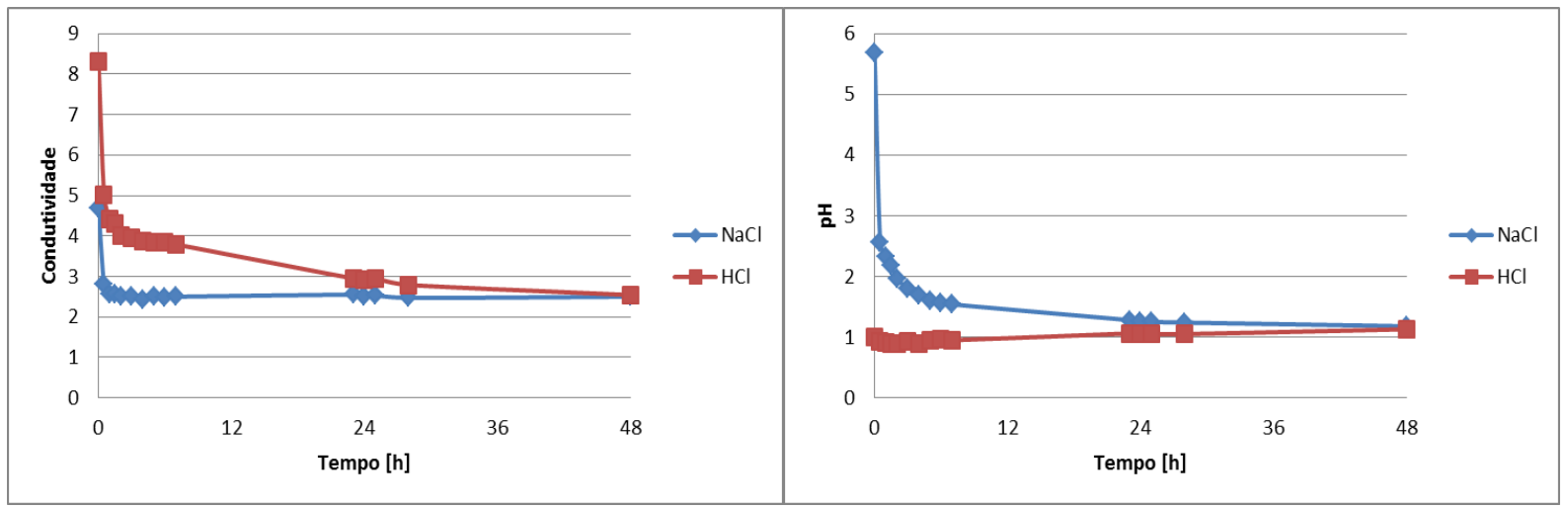

(A)

(B)

\section{CONCLUSÃO}

O presente trabalho mostra a importância de estudos para o tratamento de efluentes e apresenta dados promissores para a fabricação de membranas poliméricas com incorporação de resinas para posterior estudo, uma vez que membranas com características semelhantes possuem elevado custo comercial e podem ser utilizadas em tratamento de resíduos industriais.

\section{AGRADECIMENTOS}

As autoras agradecem a FAU/UFU, FEQ, CAPES, FAPEMIG e CNPq. 


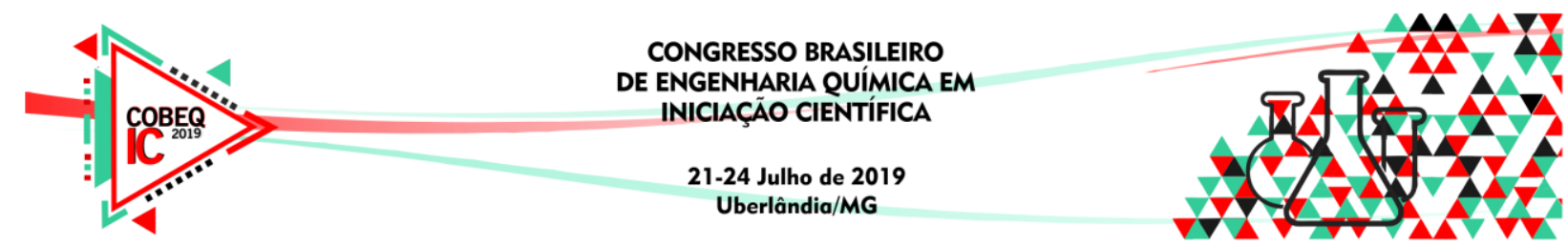

\section{REFERÊNCIAS}

ALHARATI, A. et al. Boron removal in water using a hybrid membrane process of ion Exchange resin and microfiltration without continuous resin addition. Journal of Water Process Engineering, v. 17, p. 32-39, 2017. Disponível em: <https://dx.doi.org/10.1016/j.jwpe.2017.03.002>. Acesso em: 11 abril 2019.

ANADÃO, P. Ciência e tecnologia de membranas. São Paulo: Artiliber, 199 p., 2010.

ENGEL, A. B. Síntese e caracterização de membranas compostas de triacetato de celulose através da técnica de Electrospinning. Federal University of Rio Grande do Sul, Porto Alegre, 2011.

JEONG, Y., et al. Comparison of filtration and treatment performance between polymeric and ceramic membranes in anaerobic membrane bioreactor treatment of domestic wastewater. Separation and Purification Technology, v. 199, p. 182-188, 2018. Disponível em: <https://doi.org/10.1016/j.seppur.2018.01.057>. Acesso em: 11 abril 2019.

JIANG, Z., et al. Novel sulfonated poly(ether ether ketone)s containing nitrile groups and their composite membranes for fuel cells. Journal of Power Sources, v. 195, p. 4613-4621, 2010. Disponível em: <http://dx.doi.org/10.1016/j.jpowsour.2010.02.036>. Acesso em: 11 abril 2019.

KAMCEV, J. et al. Salt concentration dependence of ionic conductivity in ion Exchange Membranes. Journal of Membrane Science, v. 547, p. 123-133, 2018. Disponível em: <http://dx.doi.org/10.1016/j.memsci.2017.10.024>. Acesso em: 11 abril 2019.

MEIRELES, I. T. et al. Impact of biopolymer purification on the structural characteristics and transport performance of composite polysaccharide membranes for pervaporation. Journal of Membrane Science, v. 493, p. 179-187, 2015. Disponível em: <http://dx.doi.org/10.1016/j.memsci.2015.07.011>. Acesso em: 11 abril 2019.

PARK. C. H., et al. Thin film composite membrane prepared by interfacial polymerization as an ion exchange membrane for salinity gradient power. Journal of Industrial and Engineering Chemistry, v. 59, p. 362-371, 2018. Disponível em: <https://doi.org/10.1016/j.jiec.2017.10.044>. Acesso em: 11 abril 2019.

RAN, J. Ion Exchange membranes: New developments and applications. Journal of Membrane Science, v. 522, p. 267-291, 2017. Disponível em: <http://dx.doi.org/10.1016/j.memsci.2016.09.033>. Acesso em: 11 abril 2019.

SILVA, D. E. S. L. Síntese e caracterização de membranas condutoras híbridas Baseadas em poli (éter imida) para uso em célula a combustível. Federal University of Rio de Janeiro, 2011.

VINCENT, I.; BESSARABOV, D. Low cost hydrogen production by anion exchange membrane electrolysis: A review. Renewable and Sustainable Energy Reviews, v. 81, p. 


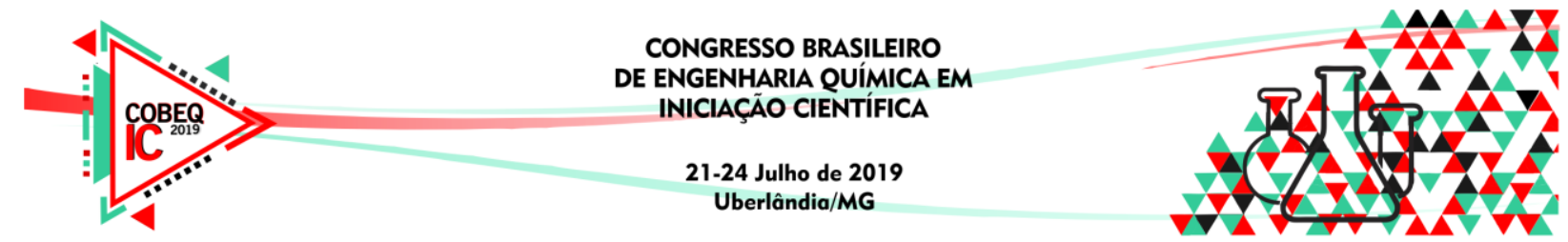

1690-1704, 2018. Disponível em: <http://dx.doi.org/10.1016/j.rser.2017.05.258>. Acesso em: 11 abril 2019.

WARSINGER D. M., et al. A review of polymeric membranes and processes for potable water reuse. Progress in Polymer Science, v. 81, p. 209-237, 2018. Disponível em: <https://doi.org/10.1016/j.progpolymsci.2018.01.004>. Acesso em: 11 abril 2019. 